\title{
Functional Mitral Stenosis: Imposture of Primary Cardiac Intimal Sarcoma
}

\author{
Poornima Vinod ${ }^{\text {a, b, e }}$, Ahmad Jabria ${ }^{\text {a }}$, Vinayak Hegde ${ }^{\mathrm{c}}$, \\ Joseph Lahorra ${ }^{\mathrm{d}}$, David Cutler ${ }^{\mathrm{c}}$
}

\begin{abstract}
Cardiac intimal sarcomas are extremely rare, remarkably aggressive and least reported type of primary malignant tumors of the heart. Cardiac intimal sarcomas are encountered more commonly in the large arterial blood vessels including pulmonary artery and aorta, and are extremely rare in the heart. The mainstay of treatment is achievement of tumor-free margins with surgical resection, which is associated with improved survival. Here, we report a 66 -year-old female with primary cardiac intimal sarcoma presented with functional mitral stenosis and heart failure. This case report emphasizes common presentation of a rare disease, and the significance of early diagnosis and timely intervention.
\end{abstract}

Keywords: Cardiac intimal sarcomas; Mitral stenosis; Heart failure; Cardiac tumors; Myxoma

\section{Introduction}

Cardiac tumors can be classified into primary and secondary (metastatic). Primary cardiac tumors are extremely rare with an incidence of $0.001-0.03 \%$ based on the autopsy findings [1]. Approximately $75 \%$ of primary cardiac tumors are benign with $50 \%$ of those being myxomas, and the remaining being fibroelastoma, lipoma, fibroma, hemangioma, rhabdomyoma, paraganglioma and teratoma [1-3]. The remaining $25 \%$ of primary cardiac tumors are malignant with sarcomas accounting for $95 \%$ and lymphomas accounting for $5 \%$ of these tumors [1]. The most common cardiac sarcoma is the angiosarcoma (37\%), while others include undifferentiated sarcoma (24\%),

Manuscript submitted June 20, 2018, accepted August 8, 2018

aDepartment of Internal Medicine, Cleveland Clinic Akron General, Akron, $\mathrm{OH}$, USA

'Inpatient Medicine, Aultman Hospital, Canton, OH, USA

'Department of Cardiology, Cleveland Clinic Akron General, Akron, OH, USA ${ }^{\mathrm{d}}$ Department of Cardiothoracic Surgery, Cleveland Clinic Akron General, Akron, $\mathrm{OH}$, USA

${ }^{\mathrm{e}}$ Corresponding Author: Poornima Vinod, Department of Internal Medicine, Cleveland Clinic Akron General, Akron, OH 44307, USA.

Email: drpoornimavinod@yahoo.com

doi: https://doi.org/10.14740/cr748w malignant fibrous histiocytoma (11-24\%), leiomyosarcoma (89\%) and osteosarcoma (3-9\%) [1]. Cardiac intimal sarcoma is the least reported type of primary cardiac sarcoma [1, 46]. However, a recent retrospective analysis by Neuville et al, showed cardiac intimal sarcomas $(42 \%)$ to be the most frequent primary cardiac sarcoma followed by angiosarcoma $(26 \%)$, undifferentiated sarcoma (22\%), synovial sarcomas $(7 \%)$, leiomyosarcomas $(2 \%)$ and peripheral neuroectodermal tumor $(1 \%)$ [7]. Cardiac intimal sarcomas are encountered more commonly in the large arterial blood vessels including pulmonary artery and aorta, and are extremely rare in the heart $[4,8-12]$.

Secondary or metastatic cardiac tumors are 20 - 40 times more common than the primary cardiac tumors [13]. Most common malignant neoplasms that metastasize to the heart and pericardium include lung and breast cancer [13]. Others malignancies, such as Hodgkin's and non-Hodgkin's lymphoma, malignant melanoma, various primary gastrointestinal malignant neoplasms, thyroid and renal neoplasms, and extracardiac sarcomas, can also involve the heart secondarily [14]. Here, we report a case of primary cardiac intimal sarcoma presenting with functional mitral stenosis and heart failure.

\section{Case Report}

A 66-year-old Caucasian female with past medical history of hypertension, hyperlipidemia and hypothyroidism presented to the emergency department with complaints of progressive exertional dyspnea for the last couple of months which had worsened in the last 2 days. She also had associated orthopnea, paroxysmal nocturnal dyspnea (PND) and exercise intolerance. The patient was hemodynamically stable on presentation with blood pressure of $108 / 75 \mathrm{~mm} \mathrm{Hg}$, pulse rate of $98 / \mathrm{min}$, temperature of $97.2^{\circ} \mathrm{F}$, respiratory rate of 16 cycles/ min and $\mathrm{SpO}_{2}$ of $98 \%$. Cardiovascular system examination revealed normal S1 and S2 without any murmurs, gallops or rubs with mild jugular venous pressure (JVP) elevation, and respiratory system exam was significant for bilateral crackles. Laboratory data are presented in Table 1 . The results of hepatic panel, renal function and lipid panel were within normal limits. An electrocardiogram showed normal sinus rhythm with occasional premature ventricular complexes (Fig. 1). She was hospitalized for suspected new-onset decompensated congestive heart failure and also to rule out pulmonary embolism in view of acute onset of dyspnea. Contrast CT chest (pulmonary 
Table 1. Initial laboratory results

\begin{tabular}{|c|c|}
\hline \multicolumn{2}{|l|}{ Complete blood count } \\
\hline White blood cells & $10.7 \times 10^{3} / \mathrm{cmm}\left(4.4 \times 10^{3}-9.7 \times 10^{3} / \mathrm{cmm}\right)$ \\
\hline Hemoglobin & $12.5 \mathrm{~g} / \mathrm{dL}(13.2-17.4 \mathrm{~g} / \mathrm{dL})$ \\
\hline Red blood cells & $3.86 \mathrm{mil} / \mathrm{cmm}(4.22-5.8 \mathrm{mil} / \mathrm{cmm})$ \\
\hline Hematocrit & $37.6 \%(39.6-50.7 \%)$ \\
\hline Platelet count & 302 thou/cmm $(150-370$ thou/cmm $)$ \\
\hline Mean corpuscular volume & $97.4 \mathrm{fl}(80-100 \mathrm{fl})$ \\
\hline Mean corpuscular hemoglobin concentration & $33.2 \%(31.9-35.6 \%)$ \\
\hline Red cell distribution width & $12.4 \%(11.8-14.5 \%)$ \\
\hline Mean corpuscular hemoglobin & $32.0 \mathrm{pg}(27.4-32.8 \mathrm{pg})$ \\
\hline \multicolumn{2}{|l|}{ Basic metabolic panel } \\
\hline Serum sodium & $141 \mathrm{mEq} / \mathrm{L}(136-145 \mathrm{mEq} / \mathrm{L})$ \\
\hline Serum potassium & $3.4 \mathrm{mEq} / \mathrm{L}(3.5-5.1 \mathrm{mEq} / \mathrm{L})$ \\
\hline Serum chloride & $104 \mathrm{mEq} / \mathrm{L}(98$ - $107 \mathrm{mEq} / \mathrm{L})$ \\
\hline Serum bicarbonate & $28 \mathrm{mEq} / \mathrm{L}(21-32 \mathrm{mEq} / \mathrm{L})$ \\
\hline Serum creatinine & $0.88 \mathrm{mg} / \mathrm{dL}(0.67-1.17 \mathrm{mg} / \mathrm{dL})$ \\
\hline Blood urea nitrogen & $16 \mathrm{mg} / \mathrm{dL}(7-18 \mathrm{mg} / \mathrm{dL})$ \\
\hline Blood glucose & $133 \mathrm{mg} / \mathrm{L}(70$ - $99 \mathrm{mg} / \mathrm{dL})$ \\
\hline Serum calcium & $9.1 \mathrm{mg} / \mathrm{dL}(8.5-10.1 \mathrm{mg} / \mathrm{dL})$ \\
\hline Serum magnesium & $2.1 \mathrm{mEq} / \mathrm{L}(1.5-2 \mathrm{mEq} / \mathrm{L})$ \\
\hline Anion gap & $12 \mathrm{mEq} / \mathrm{L}(8-16 \mathrm{mEq} / \mathrm{L})$ \\
\hline \multicolumn{2}{|l|}{ Hepatic panel } \\
\hline Aspartate aminotransferase & $26 \mathrm{IU} / \mathrm{L}(5-30 \mathrm{IU} / \mathrm{L})$ \\
\hline Alanine aminotransferase & $22 \mathrm{IU} / \mathrm{L}(5-30 \mathrm{IU} / \mathrm{L})$ \\
\hline Total bilirubin & $18 \mu \mathrm{mol} / \mathrm{L}(2-20 \mu \mathrm{mol} / \mathrm{L})$ \\
\hline Direct bilirubin & $2 \mu \mathrm{mol} / \mathrm{L}(0-6 \mu \mathrm{mol} / \mathrm{L})$ \\
\hline Serum albumin & $4 \mathrm{~g} / \mathrm{dL}(3.5-5.5 \mathrm{~g} / \mathrm{dL})$ \\
\hline Total protein & $7.5 \mathrm{~g} / \mathrm{dL}(6-8.3 \mathrm{~g} / \mathrm{dL})$ \\
\hline \multicolumn{2}{|l|}{ Cardiac markers } \\
\hline Creatinine kinase & $28 \mathrm{U} / \mathrm{L}(25-200 \mathrm{U} / \mathrm{L})$ \\
\hline Creatinine kinase-MB & $22 \mathrm{IU} / \mathrm{L}(5-25 \mathrm{IU} / \mathrm{L})$ \\
\hline Serum troponin (initial on presentation) & $<0.015 \mathrm{ng} / \mathrm{mL}(0.015-0.045 \mathrm{ng} / \mathrm{mL})$ \\
\hline Serum troponin (second at $3 \mathrm{~h}$ ) & $<0.015 \mathrm{ng} / \mathrm{mL}(0.015-0.045 \mathrm{ng} / \mathrm{mL})$ \\
\hline Serum troponin (third at $6 \mathrm{~h}$ ) & $<0.015 \mathrm{ng} / \mathrm{mL}(0.015-0.045 \mathrm{ng} / \mathrm{mL})$ \\
\hline
\end{tabular}

embolism protocol) showed no evidence of pulmonary embolism, but revealed small bilateral pleural effusion and diffuse pulmonary edema (Fig. 2).

Diuretic therapy with furosemide was initiated for symptomatic relief. Transthoracic echocardiogram (TTE) and transesophageal echocardiogram (TEE) revealed an enlarged left atrium with a $4 \times 4 \mathrm{~cm}$ multi-lobed mobile mass, causing severe functional stenosis and mitral regurgitation with mildto-moderate pulmonary hypertension (Figs. 3 and 4). Cardiac magnetic resonance imaging (MRI) showed a large oval echodensity measuring $4.1 \times 3.4 \mathrm{~cm}$ within the left atrium and appeared to be attached to the posterior mitral leaflet prolapsing during diastole (Fig. 5). The most likely differential for this mass included a large myxoma, although a thrombus could not be fully excluded. Other differentials were lymphoma, angiosarcoma and melanoma given the mass originating away from the inter-atrial septum, unlike most of the myxomas. Cardiothoracic surgery was consulted for recommendations on tumor excision. The tumor was excised with negative margins, utilizing cardiopulmonary bypass. There were no significant postoperative complications except for paroxysmal atrial fibrillation and the patient was discharged home. 


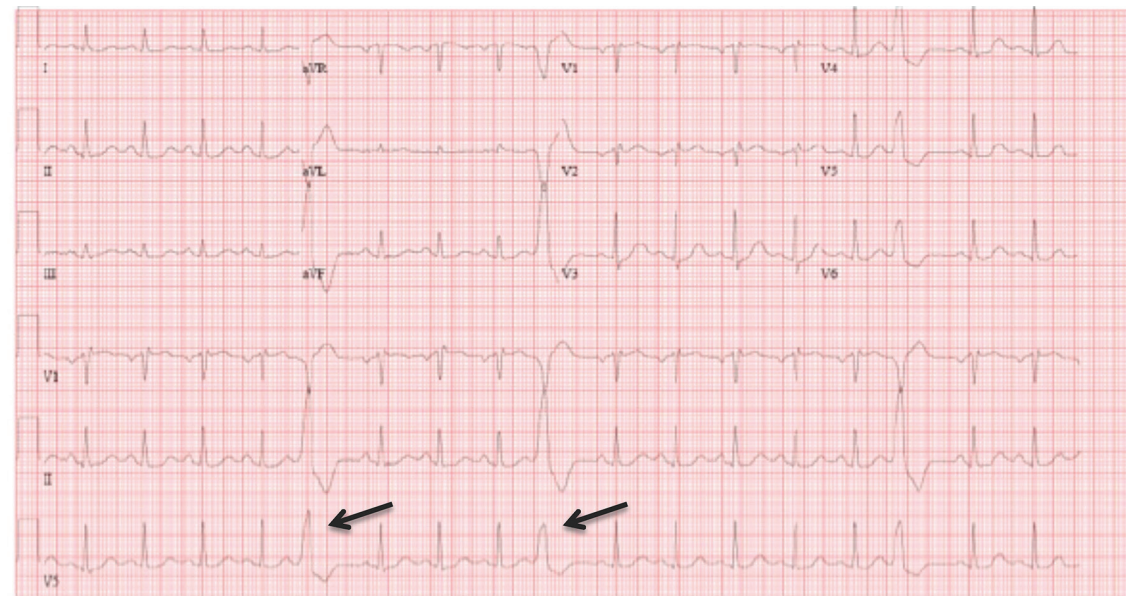

Figure 1. Electrocardiogram showing normal sinus rhythm with occasional premature ventricular complexes.
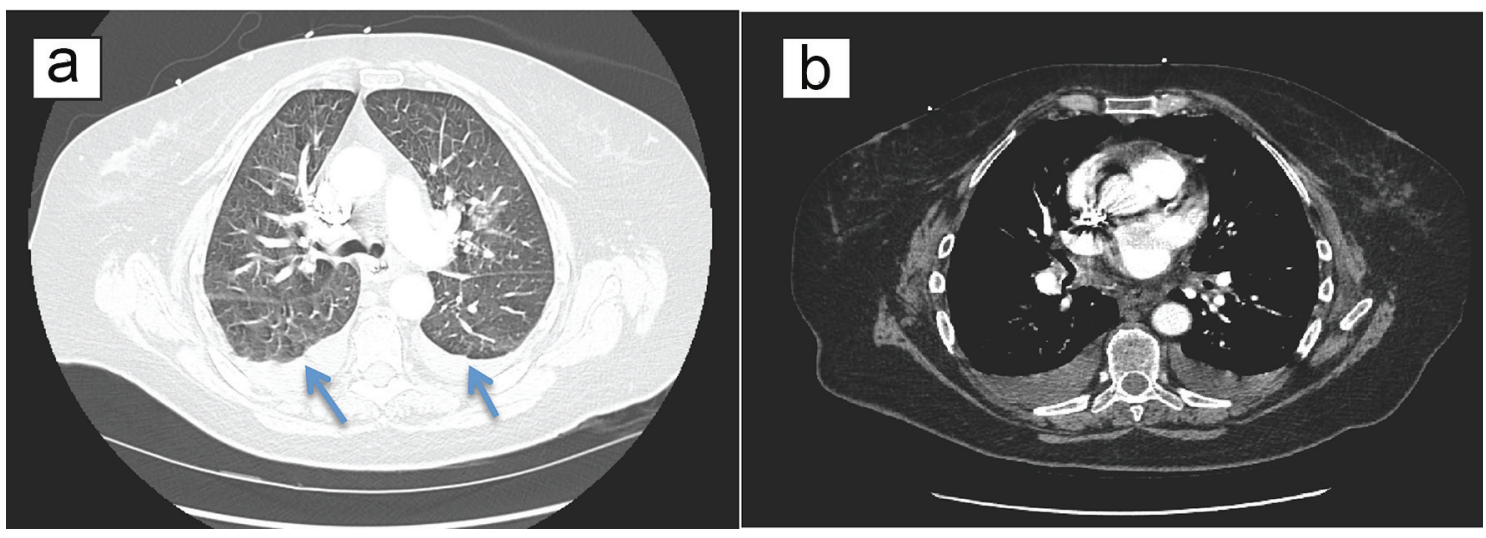

Figure 2. Computed tomography chest (pulmonary embolism protocol). (a) Small bilateral pleural effusions with diffuse pulmonary edema; (b) normal sized heart without pericardial effusion.

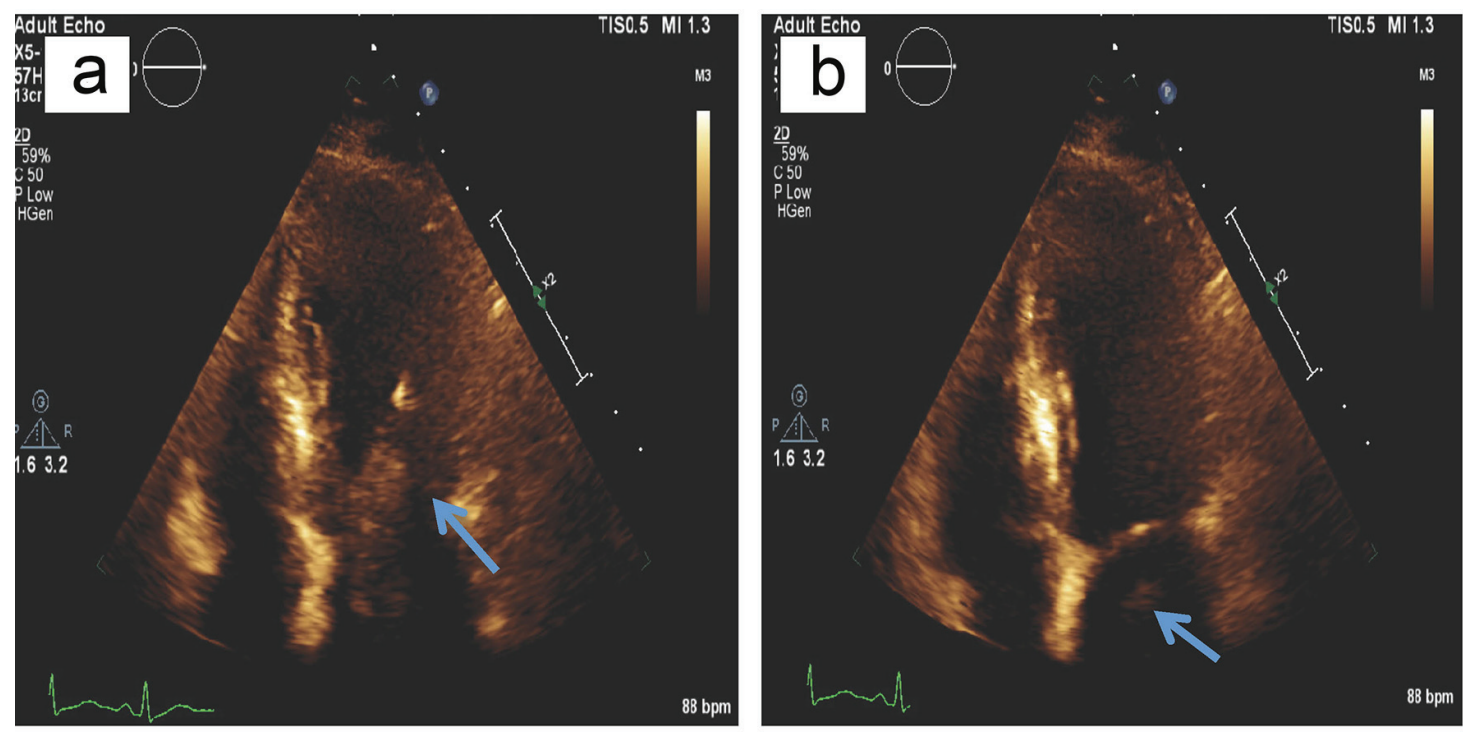

Figure 3. Transthoracic echocardiogram showing large mobile density within left atrium. (a) Moving into mitral annulus during diastole; (b) mass seen in left atrium during the systole. 

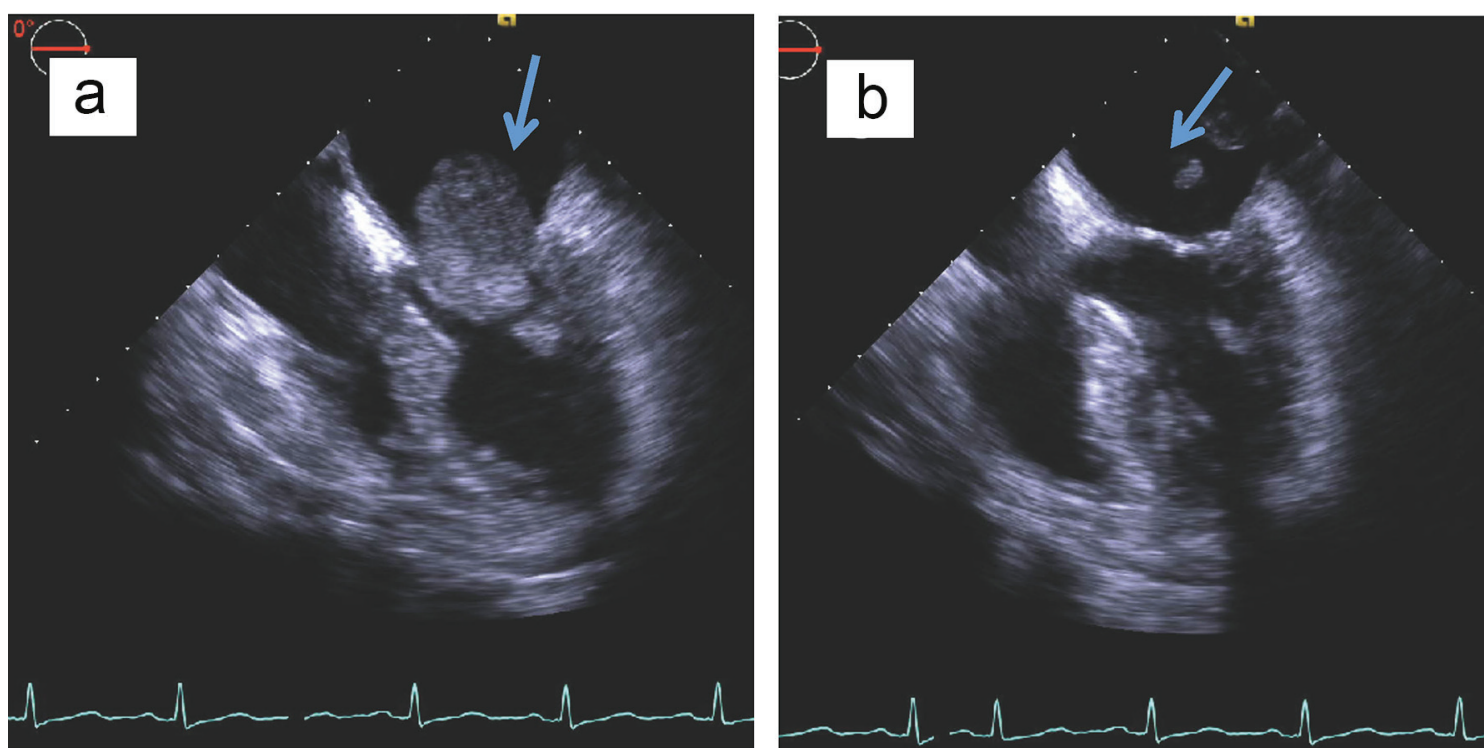

Figure 4. Transesophageal echocardiogram showing multilobed mobile large left atrial mass. (a) Mass attached above posterior mitral valve leaflet, which prolapses into left ventricular inflow during diastole; (b) mass seen in the left atrium during systole.
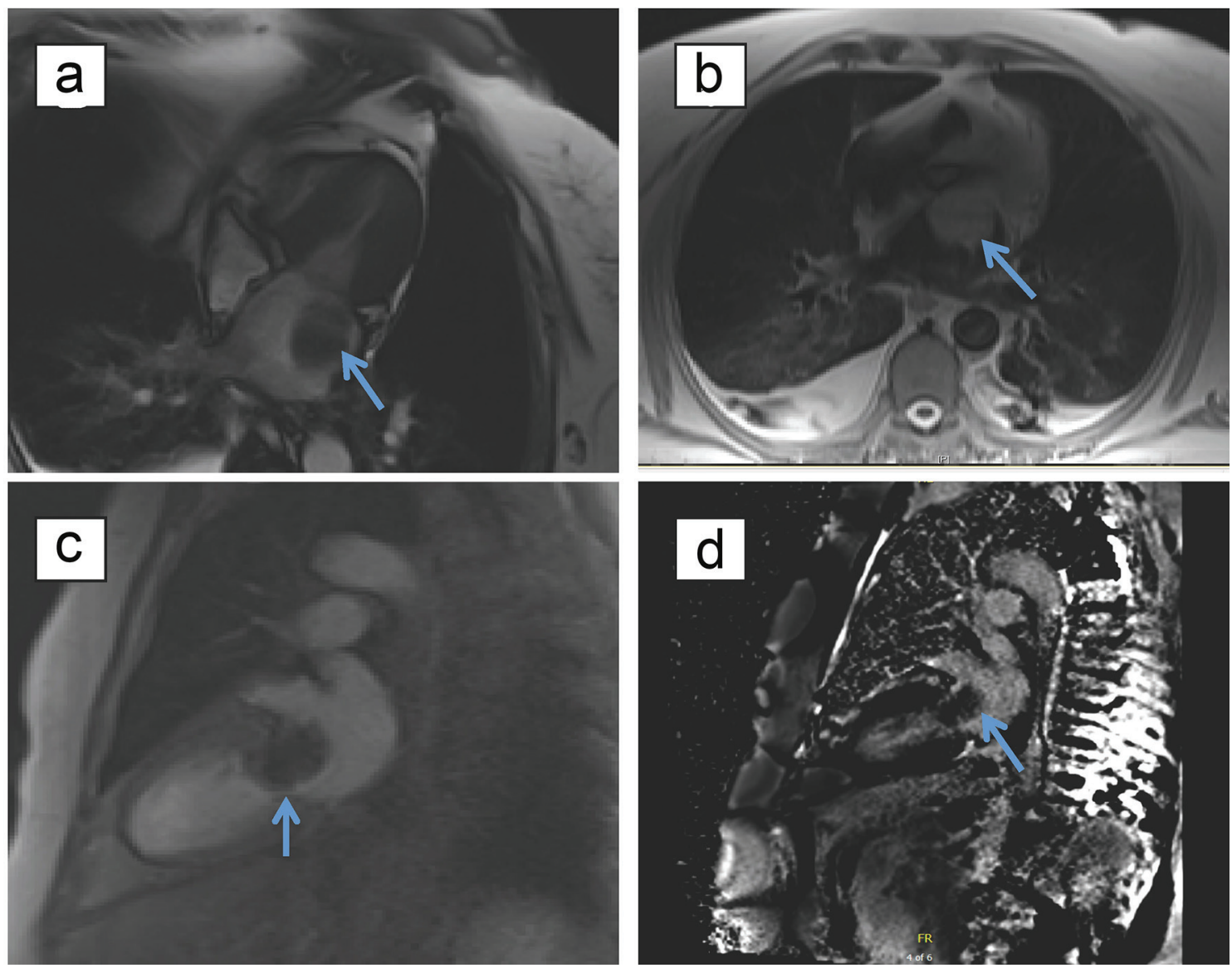

Figure 5. Magnetic resonance imaging of myocardium with and without contrast demonstrating characteristics of the mass. (a) Large oval echodensity measuring $4.1 \times 3.4 \mathrm{~cm}$ visualized within the left atrium on TRU FISP cine imaging, with possible attachment to the posterior mitral leaflet. (b) Isotense on T1-weighed spin echo imaging. (c) No enhancement of mass with first pass of gadalonium. (d) Lack of late gadolinium enhancement of mass. 

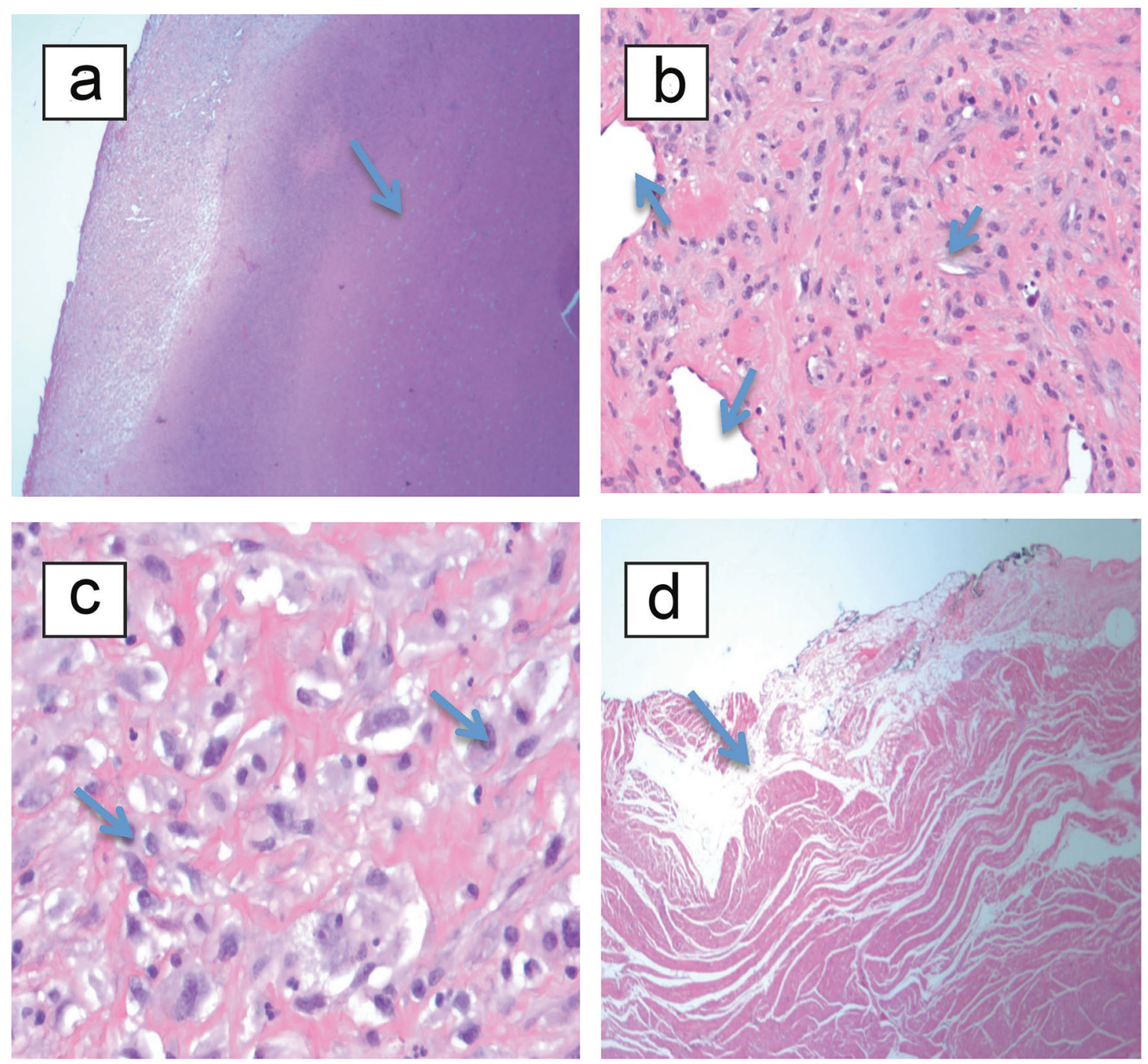

Figure 6. Histopathology pictures of cardiac intimal sarcoma showing cells arranged in spindles with high mitotic activity. (a) H\&E stain showing extensive necrosis; (b) H\&E stain showing abundant blood vessels; (c) H\&E stain showing mitotic activity approximately $3 / 10 \mathrm{hpf}$ and prominent tissue necrosis; (d) negative tumor margins.

Subsequent histopathology showed intimal sarcoma grade 3 with negative surgical margins (Fig. 6). The tumor size was approximately $5.5 \times 4.5 \times 2.5 \mathrm{~cm}$ and mitotic activity was approximately $3 / 10 \mathrm{hpf}$ with prominent tumor necrosis $(>50 \%)$. The surgery was considered to be the definitive treatment as preoperative cardiac MRI and chest CT showed no evidence for metastasis.

\section{Discussion}

This is a rare case of primary cardiac intimal sarcoma presenting with functional mitral stenosis and heart failure. Cardiac intimal sarcomas are endocardial mesenchymal tumors that most commonly arise from great vessels like the pulmonary artery or thoracic aorta and are rarely seen in the heart with most originating in the left heart $[7,8]$. Like in our case, cardiac intimal sarcomas are common in women older than 40 years of age and about $65 \%$ of those that arise in the heart originate from the left atrium away from the septal wall unlike most of the myxomas that originate from the inter-atrial septum [7]. Signs and symptoms of these tumors result from intracardiac obstruction and hence depend on their site, size, invasiveness, friability and the rate of tumor growth [12]. Although constitutional symptoms are not uncommon, which include fever, fatigue and weight loss, our patient did not have any of these symptoms. Affected individuals may also present with signs of systemic embolization, splenic and renal infarct, transient ischemic attacks and strokes [12]. Other uncommon presentations include atrial fibrillation and other conduction abnormalities, pericardial effusion, signs and symptoms from metastasis; pulmonary metastases $(40 \%)$ and extrathoracic metastasis (20\%) involving kidneys, lymphnodes, brain and skin [12]. Patients may also be asymptomatic until later stages of the disease [8]. TTE, TEE, CT scan and cardiac MRI may aid in the diagnostic process; however, definitive diagnosis 
is established by histopathology [11]. Most cardiac sarcomas demonstrate some degree of late gadolinium enhancement on MRI, however, there was lack of late gadolinium enhancement in our case which is unusual.

Different histological subtypes of cardiac sarcomas include, but are not limited to, angiosarcoma, leiomyosarcoma, fibrosarcoma, rhabdomyosarcoma, synovial sarcoma, osteosarcoma, undifferentiated pleomorphic sarcoma and intimal sarcoma [7]. Cardiac intimal sarcoma (spindle cell tumor) is extremely rare and underreported among all cardiac tumors of the heart, and is associated with very poor prognosis. In up to $25 \%$ of the cases, cardiac intimal sarcomas could histologically mimic myxofibrosarcoma, synovial sarcoma, epitheloid leiomyosarcoma or sarcoma with rhabdoid differentiation [7]. Undifferentiated cardiac intimal sarcomas demonstrate atypical and tightly packed spindle-shaped cells arranged in long fascicles, areas of necrosis, cellular atypia and nuclear polymorphisms [12]. Furthermore, genomic profiling shows recurrent 12q13-14 amplicon involving MDM2, 4q12 amplicon involving KIT and PDGFRA, 7p12 gain involving EGFR and 9p21 deletion targeting CDKN2A [7]. Immunohistochemistry is generally positive for HMGA 2, CDK4, vimentin, osteopontin and MDM2; however, MDM2 overexpression and amplification confirmation by FISH, qPCR or aCGH is the pathognomonic finding in differentiating intimal sarcoma from other histological subtypes of cardiac sarcomas [7]. CD31, CD34 and factor VIII are typically negative, but may be positive in areas with angiosarcomatous differentiation [12].

The mainstay of treatment for cardiac intimal sarcomas includes achievement of tumor-free margins with surgical resection, which is associated with improved survival [12]. The average mean life expectancy is $3-12$ months [6]. The life expectancy is twice as long for patients who undergo complete tumor resection, which indicates that early diagnosis and treatment have important prognostic and therapeutic implications [15]. Often cardiac intimal sarcomas recur locally and metastasize early in less than 1 year [8]. Genomic analysis showing frequent alteration in genes like MDM2, PDGFRA and EGFR has led to further research on targeted therapeutic approach [7], thus, paving a way for other treatment modalities such as chemotherapy and radiation therapy for the treatment of cardiac intimal sarcomas [8]. Chemotherapy regimens that may have survival benefit in cardiac intimal sarcoma patients include, ifosfamide-epirubicin (or doxorubicin) and CyVADIC (cyclophosphamide, vincristine, doxorubicin and dacarbazine), which are mainly used for soft tissue sarcomas [16]. Gemcitabine-based chemotherapy regimen (single agent or in combination with docetaxel) can be tried as well due to the positive response observed in patients with soft tissue sarcomas $[8,17,18]$. Tyrosine kinase inhibitor such as pazopanib targeting PDGFRA can be considered for advanced disease, especially in patients who are refractory to the above drugs [8]. In 2012, results of the PALETTE trial lead to the approval of pazopanib in the USA for use in advanced non-adipocytic soft tissue sarcomas of patients who have had prior chemotherapy $[8,19]$. The PALETTE trial results showed overall survival of 12.5 months $(10.6$ - 14.8) with pazopanib versus 10.7 months $(8.7$ - 12.8) with placebo (HR: 0.86 , range: $0.67-1.11 ; \mathrm{P}=$ $0.25)[19]$.
Complications of cardiac intimal sarcoma include heart failure, arrhythmias, heart block, valvular regurgitation, cardiac rupture, sudden cardiac death and pericardial effusion with or without tamponade [20]. Factors that are associated with worse prognosis include necrosis, high mitotic count, metastasis and anatomical location of the tumor within the heart (intracavitary versus intramural) [11, 12]. Left-sided tumors usually carry a better prognosis than right-sided tumors. Most patients have metastatic disease; $80 \%$ die within 1 year [11]. Patients with complete tumor resection are known to live twice as long as those without the surgical resection [15]. There are no current definite guidelines on follow-up, but patients diagnosed with high-grade cardiac intimal sarcoma will need closer monitoring due to the high rate of recurrence.

\section{Conclusions}

Cardiac intimal sarcomas are extremely rare and remarkably aggressive primary malignant tumors of the heart with poor prognosis. The presentation is quite variable and needs high degree of clinical suspicion for timely diagnosis and intervention, which has a great impact on the prognosis. The mainstay of treatment for cardiac intimal sarcomas is achievement of tumor-free margins with surgical resection, which is associated with improved survival.

\section{Conflict of Interests}

Authors have no conflict of interest to declare.

\section{Financial Support}

None.

\section{Consent}

Informed consent was obtained from the patient for publication.

\section{References}

1. Butany J, Nair V, Naseemuddin A, Nair GM, Catton C, Yau T. Cardiac tumours: diagnosis and management. Lancet Oncol. 2005;6(4):219-228.

2. Reynen K. Frequency of primary tumors of the heart. Am J Cardiol. 1996;77(1):107.

3. Yusuf N. Is the heart truly noble? South Asian J Cancer. 2013;2(2):80-82.

4. $\quad$ Li Z, Hsieh T, Salehi A. Recurrent cardiac intimal (spindle cell) sarcoma of the left atrium. J Cardiothorac Vasc Anesth. 2013;27(1):103-107.

5. Cho GJ, Kim HJ, Kang JS. Primary cardiac sarco- 
ma in pregnancy: a case report. J Korean Med Sci. 2006;21(5):940-943.

6. Modi A, Lipnevicius A, Moorjani N, Haw M. Prolonged survival with left atrial spindle cell sarcoma. Interact Cardiovasc Thorac Surg. 2009;8(6):703-704.

7. Neuville A, Collin F, Bruneval P, Parrens M, Thivolet F, Gomez-Brouchet A, Terrier P, et al. Intimal sarcoma is the most frequent primary cardiac sarcoma: clinicopathologic and molecular retrospective analysis of 100 primary cardiac sarcomas. Am J Surg Pathol. 2014;38(4):461469.

8. Valecha G, Pau D, Nalluri N, Liu Y, Mohammad F, Atallah JP. Primary intimal sarcoma of the left atrium: an incidental finding on routine echocardiography. Rare Tumors. 2016;8(4):6389.

9. Muturi A, Kotecha V, Ruturi J, Muhinga M, Waweru W. High-grade spindle cell sarcoma of the heart: a case report and review of literature. J Cardiothorac Surg. 2015;10:46.

10. Kuurstra EJ, Mullen JC, MacArthur RG. Massive left atrial sarcoma presenting with severe congestive heart failure. Can J Cardiol. 2014;30(10):1250 e1213-1255.

11. Mehta N, Desai A, Shivdasani B, Suryawanshi S, Mehta AB, Behranwala A, Dhabhar B. Left atrial spindle cell sarcoma - case report. Indian Heart J. 2012;64(4):416419.

12. Ibrahim A, Luk A, Singhal P, Wan B, Zavodni A, Cusimano RJ, Butany J. Primary intimal (spindle cell) sarcoma of the heart: a case report and review of the literature. Case Rep Med. 2013;2013:461815.

13. Paraskevaidis IA, Michalakeas CA, Papadopoulos $\mathrm{CH}$, Anastasiou-Nana M. Cardiac tumors. ISRN Oncol.
2011;2011:208929.

14. Reynen K, Kockeritz U, Strasser RH. Metastases to the heart. Ann Oncol. 2004;15(3):375-381.

15. Burke AP, Cowan D, Virmani R. Primary sarcomas of the heart. Cancer. 1992;69(2):387-395.

16. Gupta A. Primary cardiac sarcomas. Expert Rev Cardiovasc Ther. 2008;6(10):1295-1297.

17. Pautier P, Floquet A, Penel N, Piperno-Neumann S, Isambert N, Rey A, Bompas E, et al. Randomized multicenter and stratified phase II study of gemcitabine alone versus gemcitabine and docetaxel in patients with metastatic or relapsed leiomyosarcomas: a Federation Nationale des Centres de Lutte Contre le Cancer (FNCLCC) French Sarcoma Group Study (TAXOGEM study). Oncologist. 2012;17(9):1213-1220.

18. Maki RG, Wathen JK, Patel SR, Priebat DA, Okuno SH, Samuels B, Fanucchi M, et al. Randomized phase II study of gemcitabine and docetaxel compared with gemcitabine alone in patients with metastatic soft tissue sarcomas: results of sarcoma alliance for research through collaboration study 002 [corrected]. J Clin Oncol. 2007;25(19):2755-2763.

19. van der Graaf WT, Blay JY, Chawla SP, Kim DW, BuiNguyen B, Casali PG, Schoffski P, et al. Pazopanib for metastatic soft-tissue sarcoma (PALETTE): a randomised, double-blind, placebo-controlled phase 3 trial. Lancet. 2012;379(9829):1879-1886.

20. Marques Mendes E, Ferreira A, Felgueiras P, Silva A, Ribeiro C, Guerra D, de Melo DP, et al. Primary intimal sarcoma of the left atrium presenting with constitutional symptoms. OxfMed Case Reports. 2017;2017(7):omx031. 